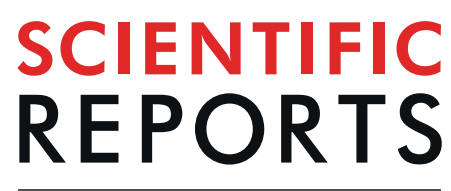

natureresearch

\title{
OPEN Aneurysmal subarachnoid haemorrhage: Effect of CRHR1 genotype on mental health-related quality of life
}

\begin{abstract}
Artur Vetkas $^{1 *}$, Ele Prans ${ }^{2}$, Sulev Kõks $\mathbb{1}^{3,4}$, Tõnu Rätsep ${ }^{1}$ \& Toomas Asser ${ }^{1}$
Quality of life (QoL) disturbances are common after aneurysmal subarachnoid hemorrhage (aSAH) both in physical and mental health domains and their causes are not clearly understood. Corticotropinreleasing hormone receptor 1 (CRHR1) is involved in stress reactivity and development of mental health disturbances after negative life-events. We performed a retrospective cohort study of long-term QoL outcomes among 125 surgically treated aSAH patients (2001-2013). QoL was assessed with Short Form Health Survey (SF-36) and compared to an age and gender matched general population. Genotyping of CRHR1 single nucleotide polymorphisms was performed (Rs7209436, Rs110402, Rs242924) and their effect on QoL scores was explored. aSAH patients experienced a reduced quality of life in all domains. CRHR1 minor genotype was associated with higher SF-36 mental health $(O R=1.31-1.6, p<0.05)$, role-emotional $(O R=1.57, p=0.04)$ and vitality scores $(O R=1.31-1.38, p<0.05)$. Association of all studied SNP's with vitality and Rs 242924 with mental health scores remained statistically significant after Bonferroni correction. Mental quality of life scores were associated with physical state of patients, antidepressant history and CRHR1 genotype. Predisposition to mental health disturbances after stressful life-events might be associated with reduced mental QoL after aSAH and selected patients could be provided advanced counselling in the recovery phase.
\end{abstract}

Aneurysmal subarachnoid haemorrhage (aSAH) causes long-term morbidity and leads to reduced quality of life $(\mathrm{QoL})^{1}$. Incidence of aSAH is around 7.9 per 100000 patient years and is showing a trend of decrease $\mathrm{e}^{2,3}$. More patients survive the subacute phase and in the long-term almost two-thirds of them are functionally independent $^{4}$. Despite survival rates improving up to $65 \%$ and physical disability decreasing among survivors, psychosocial outcomes after aSAH remain to be notably poor since up to $55 \%$ of patients report reduced quality of life years after the haemorrhage ${ }^{5}$. Up to a half of aSAH patients have mental health complaints, including depression and anxiety ${ }^{6,7}$. Only one third of the patients resume the same work ${ }^{8}$.

The cause of these changes has not been explored, although genetic background may be involved in the development of psychosocial impairments. Genes that regulate the function of the stress response system are probable moderators of the effect that adverse life events have on development of long-term mental health disturbances ${ }^{9,10}$. Corticotropin-releasing hormone $(\mathrm{CRH})$ is one of the main stress mediators in the central nervous system and plays a role in the etiology of emotional disorders ${ }^{11,12}$. Corticotropin-releasing hormone receptor 1 (CRHR1) genotype has been repeatedly associated with emotional disturbances and response to antidepressant treatment ${ }^{13-15}$. Effect of CRHR1 in major depression is moderated by a history of negative life events ${ }^{16}$ and CRHR1 genotype is associated with cortisol reactivity to stress ${ }^{17-19}$. The substantial reduction in mental health related QoL after aSAH associated with neuroendocrine dysfunction has been previously reported ${ }^{20}$. Emotional health disturbances are connected to quality of life disturbances and explain 23-47\% of QOL score reductions in aSAH ${ }^{21}$.

Few articles have been published on the genetic background of QoL disturbances after aSAH and none have studied the effect of the hypothalamic-pituitary-adrenal (HPA)-system ${ }^{22}$. We hypothesize that CRHR1 genotype will influence the mental component of quality of life after aSAH.

\footnotetext{
${ }^{1}$ Tartu University Hospital, Tartu, Estonia. ${ }^{2}$ Tartu University, Tartu, Estonia. ${ }^{3}$ Centre for Molecular Medicine and Innovative Therapeutics, Murdoch University, Perth, WA, Australia. ${ }^{4}$ The Perron Institute for Neurological and Translational Science, Perth, WA, Australia. *email: Artur.Vetkas@kliinikum.ee
} 


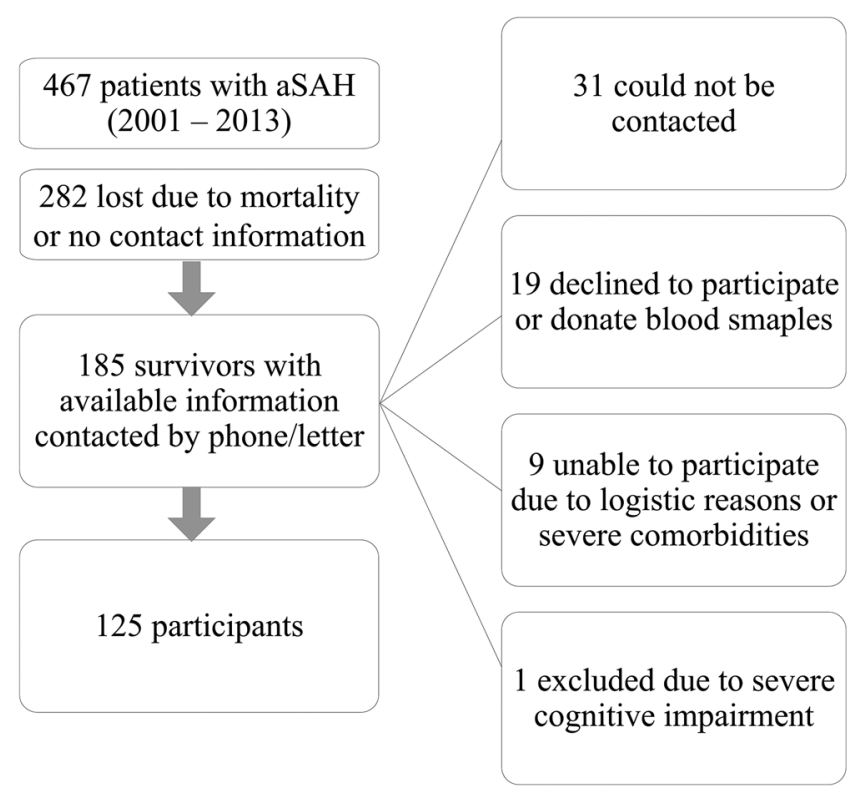

Figure 1. Study Flow Diagram.

\begin{abstract}
Methods
We performed a retrospective cohort study of long-term outcome in a group of aSAH survivors $(\mathrm{n}=125)$ surgically treated from January 2001 to November 2013 in a university clinic. All patients diagnosed with aSAH based on medical records during this period $(\mathrm{n}=467)$ were included in the study (spontaneous ICH and other SAH causes were excluded). We identified 185 survivors with available contact information, who were proposed to participate in the study. Exclusion criteria and selection protocol are presented in Fig. 1. Eventually the studied group consisted of 125 patients. Blood samples were collected after the interview by the physician. Informed consent was obtained from all participating individuals and all procedures performed in this study involving human participants were in accordance with the ethical standards and the latest Helsinki declaration. Tartu University ethics committee approval 214/T-2/2012 was given for performing this study.
\end{abstract}

General management. All patients were admitted during the acute phase of the disease. The diagnosis of aSAH was confirmed by computed tomography (CT) or lumbar puncture, and aneurysm location was assessed by CT-angiography or digital subtraction angiography. All patients were managed according to general guidelines and our protocol is previously published ${ }^{21}$. Patients were initially treated in a neurointensive care unit. Almost all patients were acutely operated upon, preferably via a pterional approach, and the aneurysms were clipped using standard microsurgical techniques. Endovascular procedures were preferentially performed in a separate institution during this time and due to this our study includes a series of clipped patients.

Procedure. Clinical variables, including Hunt and Hess grade $(\mathrm{HH})^{23}$, which is a grading system designed to predict prognosis and outcome in aSAH, were recorded in medical histories during admission. Remaining data was collected during the follow-up evaluation, when patients were interviewed in person with a structured questionnaire. Patient clinical recovery was evaluated according to the modified Rankin Score (mRS) ${ }^{24}$. Patients were also questioned about treatment for emotional disorders after aSAH, comorbidities, education and social living situation (living with family/someone else or alone). Short Form Health Survey (SF-36) was used to assess the health-related quality of life (HRQoL).

SF-36 is widely used in clinical outcome research and is a validated instrument to assess general QoL. SF-36 consists of 36 questions and measures eight scales: physical functioning, role-physical, bodily pain, general health, vitality, social functioning, role-emotional, and mental health ${ }^{25,26}$. SF-36 scores are transformed by assignment of predefined weights to the different items and calculated separately for each scale. Results can range from 0 (low QoL) to 100 (high QoL). Component scores are separately calculated for mental and physical health. SF-36 questionnaire has been added as Supplementary Material. Data of the study group was compared with corresponding values from an age-matched and gender-matched group of general population ( 996 subjects) obtained from respondents of a health survey of 1,989 individuals.

Genotyping. The genomic DNA was extracted from venous blood samples in $4 \mathrm{ml}$ EDTA containing vaccuettes by using the standard salting-out method. The EDTA tubes were stored at $-20 \mathrm{C}$ until DNA extraction. Isolated DNA was dissolved in Tris-EDTA (TE) buffer. The purity and concentrations of the DNA were measured by a spectrophotometer (NanoDrop, ND-1000). The gDNA samples were aliquotted and stored at $-80 \mathrm{C}$ until usage ${ }^{27}$. Genotyping of marker single nucleotide polymorphisms (SNP) rs7209436, rs110402, rs242924 and rs242939 was carried out by using TaqMan SNP Genotyping Assay (Applied Biosystems, Foster City, CA, USA), which is a multiplex endpoint assay that detects variants of a single nucleic acid sequence. PCR reactions were run 


\begin{tabular}{|l|l|l|l|l|l|}
\hline SNP & \multicolumn{3}{|l|}{ Genotype (n) } & $\begin{array}{l}\text { Minor } \\
\text { allele (n) }\end{array}$ & $\begin{array}{l}\text { Major } \\
\text { allele (n) }\end{array}$ \\
\hline Rs7209436 & C/C (34) & C/T (69) & T/T (22) & T (91) & C (103) \\
\hline Rs110402 & G/G (29) & A/G (68) & A/A (28) & A (96) & G (97) \\
\hline Rs242924 & G/G (31) & G/T (67) & T/T (27) & T (94) & G (98) \\
\hline
\end{tabular}

Table 1. CRHR1 allele distribution $(\mathrm{n}=125)$. Abbreviations: CRHR1 - corticotropin-releasing hormone receptor $1, \mathrm{SNP}$ - single nucleotide polymorphism.

on the ViiA7 instrument (Applied Biosystems, Foster City, CA, USA) by using the following cycling parameters: after the first step at $95 \mathrm{C}$ for 10 minutes, 40 cycles of denaturation at $92 \mathrm{C}$ for 15 seconds and extension at $60 \mathrm{C}$ for 1 minute. Genomic DNA ( $20 \mathrm{ng} / \mathrm{ul})$ was amplified in a total volume of $10 \mathrm{ul}$ containing $1 \times$ Amplification Master Mix (Applied Biosystems, Foster City, CA, USA) and $1 \times$ probe. Genotypes were analysed by using the allelic discrimination function of the system (Table 1).

Statistics. Student's t-test was used to determine the associations between the subscale scores of the questionnaires and clinical/sociodemographic factors and compare the SF-36 mean scores of the patients with age and gender matched general population. All continuous variables were controlled for normality using Shapiro-Wilk's $\mathrm{W}$ test. Beta-binomial regression analysis was performed to describe the association of CRHR1 genotype with SF-36 scale scores and calculate odds ratios. In the SNP analysis we chose between additive/dominant/recessive model based on the AIC (Akaike information criterion) of the unadjusted model. In the analysis of SF-36 results, an odds ratio (OR) higher than 1, indicates a better quality of life in the respective group (recessive model - minor allele homozygote; dominant model - major allele homozygote; additive model - OR for heterozygotes, which is multiplied in case of minor allele addition); odds ratio lower than 1 indicates a reduced outcome in SF-36 scales. More precisely, OR shows what is the probability of receiving a higher score in the selected scale by 1 point ( 1 point bring equal to 5 points in physical functioning, vitality, general health scales; 25 points in role-physical scale; about 11 points in pain scale; about 33 points in role-emotional scale, 12,5 points in social functioning scale and about 8 points in emotional wellbeing scale $)^{28,29}$. Results were considered significant if $\mathrm{p}<0.05$. The $\mathrm{p}$-values that survived the Bonferroni correction are marked in bold. Pearson's correlation and multiple logistic regression models were used to study the impact of genotype (frequency of minor alleles), sociodemographic and clinical factors on SF-36 scores. Statistical analysis was performed with Stata 14.2 (StataCorp LLC) and SPSS 24 (IBM).

\section{Results}

Patient and aSAH characteristics are presented in Table 2. Most were female $(70 \%, \mathrm{n}=88)$ and the mean age at the time of the hemorrhage was 54 years $(S D \pm 13$; range $24-82$ years). The mean time between initial admission and the study was 4 years $(\mathrm{SD} \pm 2.8$; range $1-13$ years). 51 patients $(41 \%)$ were evaluated later than 3 years from ictus. Most of the patients (78\%) had more than 10-years of education. Only 1 patient had a previous diagnosis of depression based on the medical histories available from 2009. The mean age of the patients at the time of follow-up was 58 years $(S D \pm 12$, range $26-82) .78 \%(n=97)$ of the patients were living with family or somebody else. $41 \%(\mathrm{n}=51)$ of the patients required daily help. The most common comorbidities were hypertension $(67 \%)$, joint pain $(14 \%)$ and diabetes $(7 \%) .24 \%(n=30)$ saw a psychologist or psychiatrist and $38 \%(n=30)$ used antidepressants during recovery. There was no statistically significant difference between minor and major CRHR1 genotypes and sociodemographic characteristics.

Of the patients, $55 \%(n=68)$ had a mRS score of $0-2$ and $38 \%(n=48)$ had a score of $3 . m R S$ score was worse among women $(2.5(\mathrm{SD}=0.8)$ vs $2.1(\mathrm{SD}=0.8), \mathrm{p}=0.019)$ and those requiring daily help $(3.1(\mathrm{SD}=0.5)$ vs 2.0 $(\mathrm{SD}=0.7), \mathrm{p}<0.001)$.

Quality of life scores. Quality of life scores of patients measured with SF-36 were significantly lower than the general population scores on all scales, except mental health (Table 3). Physical health scores and role limitation scores due to physical and emotional problems were affected the most. The mean SF-36 summary measures were: physical health component score (PCS-36) - $43(\mathrm{SD} \pm 9.6)$ and mental health component score (MCS-36) - $48.6(\mathrm{SD} \pm 9.4)$.

Being older than 55 years old at ictus was associated with a worse physical functioning score (mean 54 $(\mathrm{SD} \pm 25.4)$ vs $68(\mathrm{SD} \pm 25), \mathrm{p}=0.003)$ and a worse PCS-36 score (mean $40.6(\mathrm{SD} \pm 9.4)$ vs $44.6(\mathrm{SD} \pm 9.5)$, $\mathrm{p}=0.024)$.

Being female was associated with a worse physical functioning score (mean 56.9 (SD \pm 26.4 ) vs 76.6 $(\mathrm{SD} \pm 19.1), \mathrm{p}<0.001)$; role-physical score (mean $32.4(\mathrm{SD} \pm 38.6)$ vs $51.4(\mathrm{SD} \pm 45.6), \mathrm{p}=0.019)$; mental health score (mean $64.9(S D \pm 18.9)$ vs $74.1(S D \pm 13.7), \mathrm{p}=0.08)$ and a worse PCS-36 score (mean $41.6(S D \pm 9.2)$ vs $46.8(\mathrm{SD} \pm 9.5), \mathrm{p}=0.005)$.

Having more than 3 years from aSAH to evaluation was associated with a worse physical functioning score (mean 58.3 ( $\mathrm{SD} \pm 26.7)$ vs $67.4(\mathrm{SD} \pm 24.5), \mathrm{p}=0.048)$; a worse general health score (mean $43(\mathrm{SD} \pm 20.5)$ vs 54.2 $(\mathrm{SD} \pm 21.1), \mathrm{p}=0.003)$; and a worse PCS-36 score (mean $40.8(\mathrm{SD} \pm 8.8)$ vs $45.4(\mathrm{SD} \pm 9.9), \mathrm{p}=0.008)$. The difference in physical functioning score became statistically insignificant after adjustment for age.

Hypertension was associated with a worse physical functioning score (mean 58.9 ( $\mathrm{SD} \pm 25)$ vs 70.9 ( $\mathrm{SD} \pm 26.3$ ), $\mathrm{p}=0.018$ ). Diabetes was also associated with a worse physical functioning score (mean $40(\mathrm{SD} \pm 24.1)$ vs 64.6 $(\mathrm{SD} \pm 25.4), \mathrm{p}=0.016)$. Having joint pains or rheumatoid arthritis was associated with a worse role-physical score (mean $18.1(\mathrm{SD} \pm 26.9)$ vs $41.5(\mathrm{SD} \pm 42.8), \mathrm{p}=0.004)$. 


\begin{tabular}{|c|c|c|c|}
\hline Characteristic & & $\mathbf{N}$ & $\%$ \\
\hline Male & & 37 & 30 \\
\hline Female & & 88 & 70 \\
\hline \multirow{5}{*}{ Hunt Hess score } & 1 & 17 & 14 \\
\hline & 2 & 66 & 53 \\
\hline & 3 & 23 & 18 \\
\hline & 4 & 14 & 11 \\
\hline & 5 & 5 & 4 \\
\hline \multirow{6}{*}{ Aneurysm location } & ICA & 40 & 32 \\
\hline & AcomA & 44 & 35 \\
\hline & MCA & 22 & 18 \\
\hline & ACA & 8 & 6 \\
\hline & $\mathrm{BA}$ & 9 & 7 \\
\hline & VA & 2 & 2 \\
\hline Intracerebral haemorrhage & & 22 & 18 \\
\hline Symptomatic vasospasm & & 34 & 27 \\
\hline \multirow{2}{*}{ Hydrocephalus } & acute & 43 & 34 \\
\hline & chronic & $14^{*}$ & 11 \\
\hline \multirow{5}{*}{ Modified Rankin Score } & 0 & 4 & 3 \\
\hline & 1 & 7 & 6 \\
\hline & 2 & 57 & 46 \\
\hline & 3 & 49 & 39 \\
\hline & 4 & 8 & 6 \\
\hline
\end{tabular}

Table 2. Patient $(n=125)$ and aSAH characteristics. Abbreviations: ICA internal carotid artery, AcomA anterior communicating artery, MCA middle cerebral artery, ACA anterior cerebral artery, BA basilar artery, VA vertebral artery, aSAH aneurysmal subarachnoid haemorrhage. *These 14 patients required ventriculoperitoneal shunting after aSAH.

\begin{tabular}{|l|l|l|l|l|l|}
\hline SF-36 scales & $\begin{array}{l}\text { Mean aSAH } \\
(\mathbf{n = 1 2 5})\end{array}$ & $\begin{array}{l}\text { SD } \\
\text { aSAH }\end{array}$ & $\begin{array}{l}\text { Mean population } \\
(\mathbf{n = 9 9 6 )}\end{array}$ & SD population & $\mathbf{p}$ \\
\hline Physical Functioning & 62.8 & 25.9 & 79 & 25.8 & $<0.001$ \\
\hline Role-Physical & 38 & 41.4 & 71.4 & 39.1 & $<0.001$ \\
\hline Bodily Pain & 66.2 & 27.7 & 72.6 & 26.4 & 0.008 \\
\hline General Health & 48.6 & 21.4 & 56.3 & 19.2 & $<0.001$ \\
\hline Vitality & 51.3 & 20 & 55 & 18.9 & 0.03 \\
\hline Social Functioning & 72.1 & 24.5 & 77.4 & 28.6 & 0.01 \\
\hline Mental Health & 67.7 & 17.9 & 69.4 & 17.8 & 0.31 \\
\hline Role-Emotional & 53.1 & 42 & 76.3 & 36.8 & $<0.001$ \\
\hline
\end{tabular}

Table 3. Short Form Health Survey 36 results among patients and gender/age matched general population. Abbreviations: SF-36 - Short Form Health Survey 36, aSAH - aneurysmal subarachnoid haemorrhage, SD standard deviation, $\mathrm{p}-\mathrm{P}$ value.

mRS score was negatively correlated to all SF-36 scales with -0.62 for physical functioning, -0.47 for role-physical, -0.45 for general health and -0.45 for role-emotional $(\mathrm{p}<0.001)$. Correlations with mental health, vitality, social functioning scales and pain were below $-0.4(\mathrm{p}<0.001)$.

Association of CRHR1 genotype with SF-36 outcomes. In beta-binomial regression analysis we explored the association of CRHR1 genotype with SF-36 quality of life scores (Table 4). CRHR1 minor alleles (rs7209436, rs110402, and rs242924) were associated with higher mental health scores $(\mathrm{OR}=1.31-1.6, \mathrm{p}<0.05)$ in additive and recessive models; and higher vitality scores $(\mathrm{OR}=1.31-1.38, \mathrm{p}<0.05)$ in the additive model. Rs7209436 minor alleles were associated with a higher role-emotional score $(\mathrm{OR}=1.57,95 \% \mathrm{CI}, 1.01-2.44$, $\mathrm{p}=0.044)$ in the additive model and $\mathrm{rs} 110402$ major alleles with a lower role-emotional score $(\mathrm{OR}=0.43,95 \%$ CI, $0.21-0.87, \mathrm{p}=0.019)$ in the dominant model. The results remained statistically significant after adjustment for gender, neurological state at admission $(\mathrm{HH})$, patient age and time from aSAH to evaluation.

Effect of CRHR1 genotype on mental health (Rs242924) and vitality scales (all SNP's) remained statistically significant after Bonferroni correction for multiple comparisons. Homozygotes for Rs 242924 minor allele had higher mental health scores $(\mathrm{OR}=1.6,95 \% \mathrm{CI}, 1.14-2.24, \mathrm{p}=0.007)$. Homozygotes for minor alleles of Rs7209436 (OR = 1.9, $\mathrm{p}=0.002)$, Rs110402 $(\mathrm{OR}=1.69, \mathrm{p}=0.008)$ and $\mathrm{Rs} 242924(\mathrm{OR}=1.77, \mathrm{p}=0.005)$ had higher vitality scores. 


\begin{tabular}{|c|c|c|c|c|c|c|c|c|}
\hline SNP & Allele & Model & OR & 95\% CI & p & OR* & 95\% CI* & $\mathrm{p}^{*}$ \\
\hline \multicolumn{9}{|c|}{ Mental health } \\
\hline Rs7209436 & Minor & Additive & 1.31 & $1.07-1.6$ & 0.009 & 1.31 & $1.07-1.6$ & 0.009 \\
\hline Rs110402 & Minor & Additive & 1.29 & $1.06-1.57$ & 0.011 & 1.26 & $1.04-1.54$ & 0.019 \\
\hline Rs242924 & Minor & Recessive & 1.6 & $1.14-2.24$ & 0.006 & 1.59 & $1.14-2.22$ & 0.007 \\
\hline \multicolumn{9}{|l|}{ Vitality } \\
\hline Rs7209436 & Minor & Additive & 1.38 & $1.13-1.7$ & 0.002 & 1.38 & $1.13-1.69$ & 0.002 \\
\hline Rs110402 & Minor & Additive & 1.31 & $1.07-1.6$ & 0.008 & 1.31 & $1.07-1.6$ & 0.009 \\
\hline Rs242924 & Minor & Additive & 1.33 & $1.09-1.62$ & 0.005 & 1.32 & $1.08-1.62$ & 0.006 \\
\hline \multicolumn{9}{|c|}{ Role-emotional } \\
\hline Rs7209436 & Minor & \begin{tabular}{|l|} 
Additive \\
\end{tabular} & 1.57 & $1.01-2.44$ & 0.044 & 1.53 & $0.98-2.4$ & 0.063 \\
\hline Rs110402 & Major & Dominant & 0.43 & $0.21-0.87$ & 0.019 & 0.44 & $0.22-0.91$ & 0.026 \\
\hline
\end{tabular}

Table 4. Association of genotype with Short Form Health Survey 36 scales (only statistically significant results are reported). Abbreviations: SNP - single nucleotide polymorphism, OR-odds ratio, CI-confidence interval, $\mathrm{p}$-P-value. *-values adjusted for sex, Hunt Hess score, patient age and time of evaluation from aSAH. P-values that survived the Bonferroni correction are marked with bold.

\begin{tabular}{|l|l|l|l|}
\hline Genotype & Mental health & Vitality & Role-emotional \\
\hline Rs7209436 \\
\hline MM & $63.5 \pm 24.0$ & $43.4 \pm 15.3$ & $41.2 \pm 40.5$ \\
\hline $\mathrm{mM}$ & $67.2 \pm 18.5$ & $52.5 \pm 21.4$ & $55.6 \pm 43.1$ \\
\hline $\mathrm{mm}$ & $75.5 \pm 15.4$ & $59.5 \pm 17.6$ & $63.6 \pm 36.1$ \\
\hline Rs110402 & $63.3 \pm 17.4$ & $44.0 \pm 15.1$ & $36.8 \pm 39.5$ \\
\hline $\mathrm{MM}$ & $66.6 \pm 18.5$ & $51.7 \pm 22.1$ & $55.9 \pm 42.6$ \\
\hline $\mathrm{mM}$ & $74.7 \pm 14.9$ & $57.9 \pm 16.3$ & $63.1 \pm 38.2$ \\
\hline $\mathrm{mm}$ & $65.9 \pm 17.9$ & $43.7 \pm 15.3$ & n/a \\
\hline Rs242924 & $65.3 \pm 18.3$ & $52.0 \pm 21.9$ & n/a \\
\hline $\mathrm{MM}$ & $75.7 \pm 14.2$ & $58.1 \pm 16.6$ & n/a \\
\hline $\mathrm{mM}$ &
\end{tabular}

Table 5. Average scores of SF-36 QoL scales associated with CRHR1 genotype according to major and minor alleles. Abbreviations: $\mathrm{n} / \mathrm{a}$ - not associated. $\mathrm{MM}$ - homozygote for major allele, $\mathrm{mM}$ - heterozygote, $\mathrm{mm}$ homozygote for minor allele.

Patients with more minor alleles of rs7209436, rs110402, and rs242924 had higher mental QoL scores. Homozygotes for minor allele of Rs 242924 had a higher mental health score compared to major allele carriers - 76 vs 66. Homozygotes for minor alleles of Rs7209436, Rs110402 and Rs 242924 had higher vitality scores (60 vs 43 ; 58 vs 44; and 58 vs 44, respectively). Same trend is observable for other alleles in Table 5. rs 242939 did not show a statistically significant association with SF-36 scores. TAT-haplotype, formed by the three minor alleles, did not show any statistically significant effect on the quality of life scores.

Factors influencing mental QoL. The best multiple regression analysis models for SF-36 scales associated with CRHR1 genotype (Table 6) included mRS score, physical health component score, antidepressant usage history and CRHR1 genotype (number of minor alleles), with $\mathrm{R}^{2}=0.36$ for role-emotional, $\mathrm{R}^{2}=0.32$ for vitality and $\mathrm{R}^{2}=0.3$ for mental health score, all $\mathrm{p}<0.001$ (Table 6). Minor allele count of Rs110402 was associated with role-emotional score $(\beta=0.15, \mathrm{p}=0.044)$ and of Rs7209436 with vitality score $(\beta=0.23, \mathrm{p}=0.003)$. PCS-36 score was associated with role-emotional $(\beta=0.45, \mathrm{p}<0.001)$, vitality $(\beta=0.5, \mathrm{p}<0.001)$ and mental health scores $(\beta=0.26, \mathrm{p}=0.005)$. $\mathrm{mRS}$ score was associated with role-emotional $(\beta=-0.19, \mathrm{p}=0.032)$ and mental health scores $(\beta=-0.23, p=0.013)$. Antidepressant usage history was associated with mental health score $(\beta=-0.23$, $\mathrm{p}=0.007)$. Sociodemographic factors, aneurysm location and comorbidities were not associated with SF- 36 mental scale outcomes in multiple regression analysis.

\section{Discussion}

In this retrospective cohort study, we describe the effect of CRHR1 gene polymorphisms on long-term quality of life outcomes after aSAH measured with SF-36 questionnaire. Beta-binomial regression analysis showed that CRHR1 genotype (rs7209436, rs110402, and rs242924) significantly affected mental quality of life outcomes after aSAH in studied patients. CRHR1 minor genotype carriers had higher quality of life scores in mental health, role-emotional and vitality scales, compared to the more common alleles. Rs110402 major genotype increased the risk of a worse score in role-emotional scale. Results remained statistically significant after adjustment for gender, neurological state at admission $(\mathrm{HH})$, patient age and time from aSAH to evaluation. Effect of CRHR1 genotype on mental health (Rs242924) and vitality scales (all SNP's) remained statistically significant after Bonferroni correction. 


\begin{tabular}{|c|c|c|c|c|c|}
\hline Variables & B & SE & $\beta$ & p-value & $\mathbf{R}^{2}$ \\
\hline \multicolumn{6}{|l|}{ Role-Emotional } \\
\hline PCS-36 & 1.96 & 0.37 & 0.45 & $<0.001$ & \multirow{3}{*}{0.36} \\
\hline mRS & -15.56 & 7.17 & -0.19 & 0.032 & \\
\hline Rs110402 & 9.43 & 4.64 & 0.15 & 0.044 & \\
\hline \multicolumn{6}{|l|}{ Vitality } \\
\hline PCS-36 & 1.04 & 0.16 & 0.5 & $<0.001$ & \multirow{2}{*}{0.32} \\
\hline Rs7209436 & 6.85 & 2.3 & 0.23 & 0.003 & \\
\hline \multicolumn{6}{|l|}{ Mental Health } \\
\hline PCS-36 & 0.48 & 0.17 & 0.26 & 0.005 & \multirow{3}{*}{0.3} \\
\hline Antidepressants & -8.41 & 3.06 & -0.23 & 0.007 & \\
\hline mRS & -8.13 & 3.23 & -0.23 & 0.013 & \\
\hline
\end{tabular}

Table 6. Multiple regression for SF-36 scales associated with CRHR1 genotype.

In our study, aSAH patients scored significantly lower on all SF-36 scales when compared to age and gender matched general population, except mental health where the difference did not reach statistical significance. We describe a more pronounced effect of aSAH on the physical component of QoL. Age, female gender, time from aSAH and comorbidities were associated with worse physical scale and general health scores. Female gender was associated with worse mental health. All SF-36 scales were negatively correlated to mRS score. Compared to a Swedish population studied with SF-36 after ischemic stroke, aSAH patients scored higher on physical function, but lower in mental health scales ${ }^{30}$. When compared to a group of 4-year myocardial infarction survivors aged under 65 years the biggest difference presented in role-limitation scores, with aSAH patients scoring lower ${ }^{31}$. Our patient group scored somewhat lower in the mental health scale of SF-36 than the age and gender matched general population, but the difference did not reach statistical significance. Elsewhere we have shown that when studied with a validated emotional health survey (EST-Q), which is based on DSMIV and ICD-10 diagnostic criteria, the same patient group exhibited an almost 3 times higher prevalence of depression and anxiety symptoms as an age and gender matched population. SF-36 mental health scale score consists of five questions (24-26, 28, 30). The shortage of statistical difference in detailed analysis of mental health scale depended on a better result of the study population in question 30 (amount of time spent being happy in the last 4 weeks). Patients scored higher than the general population on this sole question $-51(\mathrm{SD} \pm 25.3)$ vs $46.4(\mathrm{SD} \pm 27.8), \mathrm{p}=0.03$. When question 30 was excluded and the remaining four questions averaged, the patient group scored significantly lower than the general population $-71.8(\mathrm{SD} \pm 19.5)$ vs $75.2(\mathrm{SD} \pm 18.4), \mathrm{p}=0.03$.

Role-emotional and vitality scores were substantially lower among aSAH patients and were significantly affected by CRHR1 genotype. Role-emotional scale shows the subjective limitations people add to daily activities due to perceived mental problems. Vitality scale is a measure of energy/fatigue and it is often reduced after severe illness $^{32}$. Fatigue could present in patients due to a state of mental exhaustion from having to deal with the processes of rehabilitation and adaptation to a new situation.

The three scales of SF-36, that reflect on the mental component of quality of life, were affected by CRHR1 genotype. Other factors that influenced the results, based on the multiple regression analysis, were modified Rankin scale, PCS-36 score and history of antidepressant usage. Two thirds of the variables affecting mental QoL scores remained unknown. It was previously reported that depression and fatigue have a significant role in mental QoL score reductions measured with SF-36, explaining $42 \%$ to $47 \%$ of the variance ${ }^{21}$. Involvement of CRHR1 genotype in the present study might be explained by its association with mental health disease. CRHR1 receptor is important in regulation of HPA-axis reactivity to stress and its genotype moderates the risk of mental health disorders after stressful life events ${ }^{16,33}$, including severe illness and intensive care treatment. CRHR1 (rs1876831) genotype has been associated with post-traumatic stress disorder and depression symptoms in critical illness survivors ${ }^{34}$. This warrants for further research and separate evaluation of specific QoL modalities in patients after aSAH with focus on mental health.

Despite advances in diagnosis and early management of aSAH, outcomes for most patients remain suboptimal and long-term sequelae of the disease may be unrecognized. Quality of life in aSAH patients has been linked to both physical and mental health disturbances in the long-term ${ }^{535-39}$. Variations exist in the capacity and timing of recovery in different components of quality of life after aSAH, with emotional health requiring more time to improve $^{40}$. It was reported that productivity losses related to aSAH reached $£ 278.9$ million in the UK in $2005^{41}$. Neuropsychological disturbances can affect the ability of patients to return to work ${ }^{42,43}$, but proper rehabilitation can lead to reintegration in the long term ${ }^{44}$. We suggest that role of CRHR1 genotype warrants more research as it could help provide optimal rehabilitation and neuro-psychological support for aSAH patients.

Study limitations. Our study consisted of 125 subjects and was a retrospective design. A selection bias due to loss of follow up exists and is related to the longevity of the study, social factors and patient participation. Although, we describe an association of CRHR1 genotype with mental QoL, our study might be underpowered to draw certain conclusions. Our findings require replication in a larger cohort. It is unknown whether the studied SNP-s are functional, or they are in linkage disequilibrium with other regions. Despite mental health diagnosis being extractable from the national database, we do not know the full extent of previous emotional problems in our patient group. We lack information regarding the cognitive profile of the patients, but none of them had severe disabilities when interviewed. SF-36 is a generic questionnaire that measures multiple modalities of quality 
of life. It has a correlation around 0.7 with other QoL assessment tools ${ }^{45-47}$. Differences exist in results among QoL questionnaires and subscales exhibit ceiling and floor effects ${ }^{30,48}$. Cultural factors can also influence outcomes.

\section{Conclusion}

Results of our study suggest that CRHR1 genotype could influence mental quality of life outcomes after aSAH. rs7209436, rs110402, and rs242924 minor genotype significantly increased SF-36 mental health, role emotional and vitality scale scores This effect might be explained by CRHR1 role in the pathogenesis of emotional disorders and stress reactivity. New and improved biomarkers are needed to predict, diagnose and treat the long-term consequences of aSAH. Such biomarkers could help identify patients who would benefit from early neuropsychological rehabilitation.

Received: 22 July 2019; Accepted: 31 December 2019;

Published online: 20 January 2020

\section{References}

1. Rinkel, G. J. E. \& Algra, A. Long-term outcomes of patients with aneurysmal subarachnoid haemorrhage. Lancet Neurol. 10, 349-356 (2011)

2. Etminan, N. et al. Worldwide Incidence of Aneurysmal Subarachnoid Hemorrhage According to Region, Time Period, Blood Pressure, and Smoking Prevalence in the Population. JAMA Neurol. 76, 588-597 (2019).

3. Korja, M., Lehto, H., Juvela, S. \& Kaprio, J. Incidence of subarachnoid hemorrhage is decreasing together with decreasing smoking rates. Neurology 87, 1118-1123 (2016).

4. Nieuwkamp, D. J. et al. Changes in case fatality of aneurysmal subarachnoid haemorrhage over time, according to age, sex, and region: a meta-analysis. Lancet Neurol. 8, 635-642 (2009).

5. Noble, A. J. \& Schenk, T. Which variables help explain the poor health-related quality of life after subarachnoid hemorrhage? A meta-analysis. Neurosurgery 66, 772-783 (2010).

6. Kreiter, K. T. et al. Depressed mood and quality of life after subarachnoid hemorrhage. J. Neurol. Sci. 335, 64-71 (2013).

7. Von-Vogelsang, A. C., Forsberg, C., Svensson, M. \& Wengström, Y. Patients Experience High Levels of Anxiety 2 Years Following Aneurysmal Subarachnoid Hemorrhage. World Neurosurg. 83, 1090-1097 (2015).

8. Passier, P. E. C. A., Visser-Meily, J. M. A., Rinkel, G. J. E., Lindeman, E. \& Post, M. W. M. Life Satisfaction and Return to Work After Aneurysmal Subarachnoid Hemorrhage. J. Stroke Cerebrovasc. Dis. 20, 324-329 (2011).

9. Gerritsen, L. et al. HPA Axis Genes, and Their Interaction with Childhood Maltreatment, are Related to Cortisol Levels and StressRelated Phenotypes. Neuropsychopharmacology 42, 2446-2455 (2017).

10. Gold, P. W. The organization of the stress system and its dysregulation in depressive illness. Mol. Psychiatry 20, 32-47 (2015).

11. Wasserman, D., Wasserman, J. \& Sokolowski, M. Genetics of HPA-axis, depression and suicidality. Eur. Psychiatry 25, 278-280 (2010).

12. Naughton, M., Dinan, T. G. \& Scott, L. V. Corticotropin-releasing hormone and the hypothalamic-pituitary-adrenal axis in psychiatric disease. Handb. Clin. Neurol. 124, 69-91 (2014).

13. Liu, Z. et al. Association study of corticotropin-releasing hormone receptorl gene polymorphisms and antidepressant response in major depressive disorders. Neurosci. Lett. 414, 155-158 (2007).

14. Ishitobi, Y. et al. Association of CRHR1 and CRHR2 with major depressive disorder and panic disorder in a Japanese population. Am. J. Med. Genet. Part B Neuropsychiatr. Genet. 159B, 429-436 (2012).

15. White, S. et al. Association of CRHR1 variants and posttraumatic stress symptoms in hurricane exposed adults. J. Anxiety Disord. 27, 678-83 (2013).

16. Liu, Z. et al. Negative life events and corticotropin-releasing-hormone receptor1 gene in recurrent major depressive disorder. Sci. Rep. 3, 1-5 (2013).

17. Tyrka, A. R., Price, L. H., Gelernter, J., Anderson, G. M. \& Carpenter, L. L. Interaction of childhood maltreatment with corticotropinreleasing hormone receptor gene: effect on HPA axis reactivity. Biol. Psychiatry 66, 681-685 (2009).

18. Mahon, P. B. Genetic Association of FKBP5 and CRHR1 with Cortisol Response to Acute Psychosocial Stress in Healthy Adults. Psychopharmacol. 227, 231-241 (2013).

19. Sumner, J. A., McLaughlin, K. A., Walsh, K., Sheridan, M. A. \& Koenen, K. C. CRHR1 genotype and history of maltreatment predict cortisol reactivity to stress in adolescents. Psychoneuroendocrinology 43, 71-80 (2014).

20. Kreitschmann-Andermahr, I. et al. Quality of life and psychiatric sequelae following aneurysmal subarachnoid haemorrhage: Does neuroendocrine dysfunction play a role? Clin. Endocrinol. (Oxf). 66, 833-837 (2007).

21. Vetkas, A., Lepik, T., Eilat, T., Rätsep, T. \& Asser, T. Emotional health and quality of life after aneurysmal subarachnoid hemorrhage. Acta Neurochir. (Wien). 155, 1107-1114 (2013).

22. Alfieri, A. et al. Psychosocial and neurocognitive performance after spontaneous nonaneurysmal subarachnoid hemorrhage related to the APOE- $\varepsilon 4$ genotype: a prospective 5-year follow-up study. J. Neurosurg. 109, 1019-1026 (2008).

23. Hunt, W. E. \& Hess, R. M. Surgical Risk as Related to Time of Intervention in the Repair of Intracranial Aneurysms. J. Neurosurg. 28, 14-20 (1968)

24. Van-Swieten, J. C., Koudstaal, P. J., Visser, M. C., Schouten, H. J. \& van Gijn, J. Interobserver agreement for the assessment of handicap in stroke patients. Stroke 19, 604-7 (1988).

25. McHorney, C. A., Ware, J. E. \& Raczek, A. E. The MOS 36-Item Short-Form Health Survey (SF-36): II. Psychometric and clinical tests of validity in measuring physical and mental health constructs. Med. Care 31, 247-63 (1993).

26. McHorney, C. A., Ware, J. E., Lu, J. F. \& Sherbourne, C. D. The MOS 36-item Short-Form Health Survey (SF-36): III. Tests of data quality, scaling assumptions, and reliability across diverse patient groups. Med. Care 32, 40-66 (1994).

27. Miller, S. A., Dykes, D. D. \& Polesky, H. F. A simple salting out procedure for extracting DNA from human nucleated cells. Nucleic Acids Res. 16, 1215 (1988)

28. Najera-Zuloaga, J., Lee, D.-J. \& Arostegui, I. Comparison of beta-binomial regression model approaches to analyze health-related quality of life data. Stat. Methods Med. Res. 27, 2989-3009 (2018).

29. Arostegui, I., Núñez-Antón, V. \& Quintana, J. M. Analysis of the short form-36 (SF-36): the beta-binomial distribution approach. Stat. Med. 26, 1318-1342 (2007).

30. Almborg, A. \& Berg, S. Quality of life among Swedish patients after stroke: Psychometric evaluation of SF-36. J. Rehabil. Med. 41, $48-53$ (2009)

31. Brown, N. et al. Quality of life four years after acute myocardial infarction: short form 36 scores compared with a normal population. Heart 81, 352-8 (1999)

32. Cumming, T. B., Packer, M., Kramer, S. F. \& English, C. The prevalence of fatigue after stroke: A systematic review and meta-analysis. Int. J. Stroke 11, 968-977 (2016). 
33. Bradley, R. G. et al. Influence of child abuse on adult depression: moderation by the corticotropin-releasing hormone receptor gene. Arch. Gen. Psychiatry 65, 190 (2008).

34. Davydow, D. S. et al. A pilot investigation of the association of genetic polymorphisms regulating corticotrophin-releasing hormone with posttraumatic stress and depressive symptoms in medical-surgical intensive care unit survivors. J. Crit. Care 29, 101-106 (2014).

35. Visser-Meily, J. M. A. et al. Post-Traumatic stress disorder in patients 3 years after aneurysmal subarachnoid haemorrhage. Cerebrovasc. Dis. 36, 126-130 (2013).

36. Hedlund, M., Zetterling, M., Ronne-Engström, E., Carlsson, M. \& Ekselius, L. Depression and post-traumatic stress disorder after aneurysmal subarachnoid haemorrhage in relation to lifetime psychiatric morbidity. Br. J. Neurosurg. 25, 693-700 (2011).

37. Passier, P. E. C. A., Visser-Meily, J. M. A., Rinkel, G. J. E., Lindeman, E. \& Post, M. W. M. Determinants of health-related quality of life after aneurysmal subarachnoid hemorrhage: A systematic review. Qual. Life Res. 22, 1027-1043 (2013).

38. Meyer, B. et al. Health-Related Quality of Life in Patients with Subarachnoid Haemorrhage. Cerebrovasc. Dis. 30, 423-431 (2010).

39. Persson, H. C., Carlsson, L. \& Sunnerhagen, K. S. Life situation 5 years after subarachnoid haemorrhage. Acta Neurol. Scand. 137, 99-104 (2018).

40. He, S. \& Mack, W. J. Health-Related Quality of Life After Aneurysmal Subarachnoid Hemorrhage: Interplay Between Physical, Cognitive, and Emotional Factors. World Neurosurg. 81, 37-39 (2014).

41. Rivero-Arias, O., Gray, A. \& Wolstenholme, J. Burden of disease and costs of aneurysmal subarachnoid haemorrhage (aSAH) in the United Kingdom. Cost Eff. Resour. Alloc. 8, 6 (2010).

42. Crago, E. A. et al. Impaired Work Productivity After Aneurysmal Subarachnoid Hemorrhage. J. Neurosci. Nurs. 48, 260-268 (2016).

43. Al-Yassin, A., Ouyang, B. \& Temes, R. Depression and Anxiety Following Aneurysmal Subarachnoid Hemorrhage Are Associated With Higher Six-Month Unemployment Rates. J. Neuropsychiatry Clin. Neurosci. 29, 67-69 (2017).

44. Sonesson, B., Kronvall, E., Säveland, H., Brandt, L. \& Nilsson, O. G. Long-term reintegration and quality of life in patients with subarachnoid hemorrhage and a good neurological outcome: findings after more than 20 years. J. Neurosurg. 128, 785-792 (2018).

45. Richardson, J., Iezzi, A., Khan, M. A., Chen, G. \& Maxwell, A. Measuring the Sensitivity and Construct Validity of 6 Utility Instruments in 7 Disease Areas. Med. Decis. Mak. 36, 147-159 (2016).

46. Linde, L., Sørensen, J., Ostergaard, M., Hørslev-Petersen, K. \& Hetland, M. L. Health-related quality of life: validity, reliability, and responsiveness of SF-36, 15D, EQ-5D [corrected] RAQoL, and HAQ in patients with rheumatoid arthritis. J. Rheumatol. 35, 1528-37 (2008).

47. McDonough, C. M. et al. Comparison of EQ-5D, HUI, and SF-36-derived societal health state values among spine patient outcomes research trial (SPORT) participants. Qual. Life Res. 14, 1321-32 (2005).

48. Rautalin, M. et al. Health-related quality of life in different states of breast cancer - comparing different instruments. Acta Oncol. (Madr). 57, 622-628 (2018).

\section{Author contributions}

A.V. contributed to conception and design of the study, drafted the manuscript, prepared the tables and figures and revised the manuscript. E.P. performed the PCR analysis, wrote the genetic analysis section and revised the manuscript. S.K. contributed in organisation and revised the manuscript. T.R. contributed to conception and design of the study and revised the manuscript. T.A. contributed to conception and design of the study, contributed in organisation and revised the manuscript. All authors approved the submitted version.

\section{Competing interests}

We declare that the authors have no competing interests as defined by Nature Research, or other interests that might be perceived to influence the results and/or discussion reported in this paper. Three of the authors (E.P., S.K., T.A.) received grants from the Estonian Ministry of Education and Research. Other authors (A.V., T.R.) have no financial disclosure. E.P., S.K.: This work was supported by institutional research grants IUT20-46 of the Estonian Ministry of Education and Research. TA: This work was supported by institutional research grants IUT2-4 of the Estonian Ministry of Education and Research.

\section{Additional information}

Supplementary information is available for this paper at https://doi.org/10.1038/s41598-020-57527-4.

Correspondence and requests for materials should be addressed to A.V.

Reprints and permissions information is available at www.nature.com/reprints.

Publisher's note Springer Nature remains neutral with regard to jurisdictional claims in published maps and institutional affiliations.

Open Access This article is licensed under a Creative Commons Attribution 4.0 International License, which permits use, sharing, adaptation, distribution and reproduction in any medium or format, as long as you give appropriate credit to the original author(s) and the source, provide a link to the Creative Commons license, and indicate if changes were made. The images or other third party material in this article are included in the article's Creative Commons license, unless indicated otherwise in a credit line to the material. If material is not included in the article's Creative Commons license and your intended use is not permitted by statutory regulation or exceeds the permitted use, you will need to obtain permission directly from the copyright holder. To view a copy of this license, visit http://creativecommons.org/licenses/by/4.0/.

(c) The Author(s) 2020 